\title{
The Environmental Deposition of Severe Acute Respiratory Syndrome Coronavirus 2 in Nosocomial Settings: Role of the Aerosolized Hydrogen Peroxide
}

\author{
Amani Alnimr (D) \\ Aisha Alamri $\mathbb{D}^{2}$ \\ Khaled F Salama $\mathbb{D}^{3}$ \\ Mahmoud Radi ${ }^{4}$ \\ Huda Bukharie ${ }^{4}$ \\ Bashayer Alshehri ${ }^{5}$ \\ Ali A Rabaan ${ }^{6,7}$ \\ Mohammed Alshahrani $\mathbb{D}^{8}$ \\ 'Department of Microbiology, College of \\ Medicine \& King Fahad Hospital of the \\ University, Imam Abdulrahman Bin Faisal \\ University, Dammam, Saudi Arabia; \\ ${ }^{2}$ Department of Clinical Laboratory \\ Sciences, College of Applied Medical \\ Sciences, Imam Abdulrahman Bin Faisal \\ University, Dammam, Saudi Arabia; \\ ${ }^{3}$ Department of Environmental Health, \\ College of Public Health \& King Fahad \\ Hospital of the University, Imam \\ Abdulrahman Bin Faisal University, \\ Dammam, Saudi Arabia; ${ }^{4}$ Department of \\ Infection Control, King Fahad Hospital of \\ the University, Imam Abdulrahman Bin \\ Faisal University, Dammam, Kingdom of \\ Saudi Arabia; ${ }^{5}$ Microbiology Laboratory, \\ Johns Hopkins Aramco Healthcare, \\ Dhahran, Saudi Arabia; ${ }^{6}$ Molecular \\ Diagnostic Laboratory, Johns Hopkins \\ Aramco Healthcare, Dhahran, Saudi \\ Arabia; ${ }^{7}$ Department of Public Health and \\ Nutrition, The University of Haripur, \\ Haripur, Pakistan; ${ }^{8}$ Emergency and \\ Critical Care Department, College of \\ Medicine \& King Fahad Hospital of the \\ University, Imam Abdulrahman Bin Faisal \\ University, Dammam, Kingdom of Saudi \\ Arabia
}

Correspondence: Amani Alnimr

Email amalnimr@iau.edu.sa
Background: Data on the role of aerosolized hydrogen peroxide (AHP) systems in the control of the COVID-19 pandemic are still emerging. This study provides evidence of the environmental shedding of severe acute respiratory syndrome coronavirus 2 (SARS-CoV-2) in the hospital environment, and the efficacy of AHP to eliminate it.

Methods: A total of 324 environmental sites (224 surfaces and 100 air samples) belonging to 54 patient rooms were contextually collected and tested for genes of SARS-CoV-2 using RT-PCR assays and Xpert ${ }^{\circledR}$ Xpress SARS-CoV-2.

Results: The SARS-CoV-2 viral genome was detected in seven sites $(2.5 \%)$ of three patients' rooms, including six highly touched surfaces and one air sample. Viral shedding was directly related to the distance from the patient, with $1,1.9$, and $3.5 \%$ of samples testing positive at 3,2, and 1 meter, respectively $(P$-value $=0.02)$. None of the sites showed the viral genome following application of $6 \%$ AHP. Of note, the viral genome was detected at 2 meters of a mildly symptomatic case on a face mask in the absence of aerosol generating procedures.

Conclusion: Our data support the possible role of the hospital environment as a source of infection, and the efficacy of AHP to eliminate the virus. Further studies are needed to address the viability of the pathogen in these nosocomial sites and the cost-effectiveness of routine hospital disinfection procedures using AHP for SARS-CoV-2.

Keywords: aerosolized hydrogen peroxide, AHP, SARS-CoV-2, environmental, COVID-19, decontamination, disinfection

\section{Introduction}

Severe acute respiratory syndrome coronavirus 2 (SARS-CoV-2) is an emerging pathogen that is linked to the current pandemic of global health concern. Its ability to spread from person to person has resulted in $>200$ million confirmed cases around the world. Although the overall case-fatality is estimated to be less than $5 \%$, the disease has killed $>4.4$ million due to its efficient transmission. This infection is thought to be acquired through inhalation of respiratory droplets, as well as contact with mucous membranes following touching contaminated surfaces. ${ }^{1}$ Understanding the dynamics of transmission of the virus is evolving. A study from Singapore that detected the viral RNA on most environmental surfaces, tested in an airborne isolation suit for a patient with mildly symptomatic 
COVID-19, demonstrated the importance of environmental disinfection in controlling the epidemic. ${ }^{2}$ It is not yet certain how long the SARS-CoV-2 can persist on hospital surfaces, though initial evidence suggests it could survive up to 24 hours on inanimate wood surfaces, and up to 2 to 3 days on plastic or steel using an inoculum simulating the viral load in respiratory samples. ${ }^{3}$ The virus was also shown to persist in air for 3 hours following aerosol generating procedures such as sample collection and intubation. ${ }^{3}$ Furthermore, the infectivity of a closely related virus, SARS-CoV, was detected at 6 days following environmental inoculation, making the contaminated hospital surfaces a potential reservoir of healthcare associated COVID-19 infections. ${ }^{4}$ Virus presence in the environment can provide a source of infection when susceptible individuals touch these surfaces and then introduce the infectious particle to their mucous membranes. Extensive SARS-CoV-2 RNA contamination of environmental surfaces in hospital rooms and residential areas of patients with COVID-19 has been described. ${ }^{2,5,6}$

Effective cleaning and disinfection procedures for this coronavirus are essential to reduce its spread, thus environmental infection control measures must be implemented using bioactive disinfectants against SARS-CoV-2. A systematic review performed by Kampf et $\mathrm{al}^{7}$ demonstrated that the commonly used $70 \%$ alcohol inactivated other coronaviruses within a short time, while a contact time of 10 minutes is recommended by the US Environmental Protection Agency (EPA) for SARS-CoV $-2{ }^{8}$ Hospitals with high turnover during the epidemic waves require automated disinfecting solutions with proven efficacy against the pathogen. Hydrogen peroxide, in its vapor and dry mist forms, is an established method that is increasingly used to decontaminate hospital environments based on the evidence that supports its inactivation of viruses and bacteria. ${ }^{9}$ The dry-mist form of hydrogen peroxide relies on systems that produce the gas as small particles to circulate in air as dry aerosols. These particles can reach all the sites of a hospital room including the difficult-to-reach areas. An example of such systems is the aerosolized hydrogen peroxide (AHP) instruments, which are no-touch, pressure-aerosol generating devices based on a solution containing $6 \%$ hydrogen peroxide mixed with $<50$ ppm silver ions. ${ }^{10}$ The method produces a dry mist of the gas introduced via a unidirectional nozzle in a small particle size of $0.5 \mu \mathrm{m}$, followed by passive aeration and natural decomposition. ${ }^{10}$ The efficacy of AHP is controversial as some studies have shown a significant reduction in microbial growth, including heat-resistant bacterial spores, while others have shown incomplete eradication of pathogens. ${ }^{11,12}$ There have been no randomized trials on the effectiveness of these systems in eliminating environmental contamination or in preventing healthcareassociated infections. Based on a systematic assessment of 3,343 contaminated surfaces using the SARS-CoV-2 viral genome methods, $17 \%$ and $12 \%$ of the isolation and non-isolation facility surfaces were contaminated. ${ }^{13}$ In that study, SARS-CoV-2 survived for a variable period (2.317.9 hours) depending on humidity and temperature, irrespective of the type of contaminated surfaces, and there was $99.9 \%$ attained reduction of viral load after hydrogen peroxide application. Limited data, however, exist regarding the role of individual decontaminating agents to build up recommendations for disrupting SARS-CoV-2 transmission. This study was carried out in a high-resourced facility to evaluate the survival of SARS-CoV-2 in nosocomial environmental surfaces, and the efficacy of a hydrogen peroxide mist device in removing it, in order to support the growing evidence for optimal routine disinfection and terminal cleaning of rooms occupied by patients diagnosed with COVID-19.

\section{Materials and Methods}

\section{Research Settings}

The study was conducted at King Fahad Hospital of the University, a 550-bed academic health institution. Environmental samples were collected from airborne isolation rooms used for confirmed cases of COVID-19, as well as from other areas where those patients stayed (the emergency department room in which those cases were initially assessed, dialysis and intensive care units). Environmental surfaces, with the emphasis on highly touched areas, and air samples were collected. The influence of aerosolized hydrogen peroxide (Oxypharm Nocospray, Oxypharm, France) at a concentration of $6 \%$ was examined through detection of the CT value as a surrogate for viral load immediately prior to and within 1-hour after the decontamination process following the standard protocol as per the manufacturer recommendation. Only facilities which were occupied by confirmed cases of COVID-19 patients for at least 24 hours and less than 8 days were included. The decontamination process was routinely performed as per the institutional policy upon the needs to transfer or discharge the patient. The dose was $6 \mathrm{~mL}$ per cubic meter in multiple 
cycles as previously described. ${ }^{14}$ Patients' demographic data, triage score, and clinical data were documented as per the National Guidelines for assessing patients suspected to have COVID-19. ${ }^{15}$

The study was approved by the Institutional Review Board of Imam Abdulrahman Bin Faisal University (IRB no 2020-01-144). The study was exempt from the requirement of informed consent, as it involved only environmental samples collected during routine service and no human samples were included. The study was conducted in accordance with the Declaration of Helsinki.

\section{Sampling}

\section{Surface Sampling}

For surface samples, each site was sampled using four swabs wetted in viral transport media immediately prior to sampling after removal from the package. Pressure was applied onto the highly touched surface, eg, door handles $(3 \mathrm{~m})$, light switches $(2 \mathrm{~m})$, bed and handrails and phone sets $(1 \mathrm{~m})$, moving at least in two different directions while rotating the swab stick to cover the recommended surface area $\left(25 \mathrm{~cm}^{2}\right)$, avoiding letting the swab dry. Swabs were placed into the viral transport media (Vircell, Granada, Spain) and transported on ice pack to the laboratory for immediate storage at $-70^{\circ} \mathrm{C}$ until they were tested in batches.

\section{Air Sampling}

The air sampling method was based on the National Institute for NIOSH-0800 instruction, by using a Quick Take SKC sampling machine and an Andersen biosampler, with a flow of $28.3 \mathrm{~L}$ per 2 minutes. ${ }^{16}$ In order to avoid any interference of microorganisms or other contaminations, the bio-sampler was sterilized prior to sampling by using a disposable sterilizing gas and $70 \%$ ethanol based on the manufacturer's instructions, and then placed under a UV lamp for 20 minutes. After sterilization, the bio-sampler was placed in a sterilized cold box that was opened in the sampling location to prevent contamination. A viral transport medium (Vircell, Granada, Spain) was placed inside the biosampler and the sampling circuit was established at a distance of $100-150 \mathrm{~cm}$ from the floor. Air samples were collected at 1,2 and 3 meters from the patient after the room had been occupied for at least 24 hours and less than 8 days. The viral genome was measured prior to and after room AHP fumigation as per the routine hospital protocol.

\section{Viral Genome Testing}

Reverse transcriptase-polymerase chain reaction (RTPCR) targeting SARS-CoV-2 was performed on the environmental samples. The viral nucleic acid was initially extracted by the Bioneer extraction system (Bioneer Corporation, Korea), followed by RT-PCR assay using the Powerchek 2019-nCoV Real Time PCR kit (Kogene Biotech Co, Korea). The test detected the $E$ gene sequence of the lineage B-betacoronavirus and the $R d R p$ gene sequence specific to SARS-CoV-2. All samples showing genes were further tested using the Xpert ${ }^{\circledR}$ Xpress SARS-CoV-2 (Cepheid, Sunnyvale, CA), which identifies the $E$ gene and $N 2$ gene of SARS-CoV-2. The assays were performed following the manufacturer's recommendations using positive and negative controls in each run. The lowest cycle threshold $(\mathrm{Ct})$ values, the number of cycles required for the fluorescent signal to cross the threshold in RT-PCR, were obtained to infer viral loads; the lower the $\mathrm{Ct}$ value, the higher the viral load. ${ }^{17}$ All samples were processed under a biosafety cabinet Class II Type B to minimize the occupational risk, in a biosafety level 2 laboratory since no viral propagation or aerosol-generating procedures was performed.

\section{Statistical Analysis}

The statistical analysis was performed using the GraphPad Prism 9.0 on a sample basis. Spearman's rank correlation coefficient (rho) was measured to assess the relationship between the distance of the collection site and viral genome positivity rate. ${ }^{18} \mathrm{~A}$ significance value of $P \leq 0.05$ was used.

\section{Results}

Out of 324 sites (224 environmental swabs and 100 air samples) tested of 54 patients' rooms, seven specimens $(2.5 \%)$ were positive for the RNA of SARS-CoV-2. Of the 54 cases, five patients (9.3\%) were categorized as severely ill, 48 cases $(90.7 \%)$ were moderately ill, and one case $(1.9 \%)$ had a mild disease. None of the screened sites demonstrated evidence of viral persistence following decontamination using $6 \%$ AHP (Table 1). The frequency of isolation of the SARS-CoV-2 viral genome was noted mainly in close proximity of the patients (Table 1), and in severe cases, two out of five severely ill (40\%) as shown in Table 2, Spearman correlation coefficient $r h o=-0.976$, $P=0.02$ (Figure 1). 
Table I Frequency of Detecting SARS-CoV-2 Viral Genome in the Environment of Hospitalized COVID-I9 Patients

\begin{tabular}{|c|c|c|c|c|c|}
\hline & \multicolumn{2}{|c|}{ Prior to AHP Decontamination } & \multicolumn{2}{|c|}{ After AHP Decontamination } & \multirow[t]{2}{*}{ Total } \\
\hline & RNA Detected & RNA Not Detected & RNA Detected & RNA Not Detected & \\
\hline \multicolumn{6}{|c|}{ Within I m: } \\
\hline Surfaces & 4 & 104 & 0 & 108 & \multirow[t]{2}{*}{$4 / 115(3.5 \%)$} \\
\hline Air & 0 & 7 & 0 & 7 & \\
\hline \multicolumn{6}{|c|}{ Within 2 m: } \\
\hline Surfaces & 1 & 100 & 0 & 101 & \multirow[t]{2}{*}{$2 / 108(1.9 \%)$} \\
\hline Air & 1 & 6 & 0 & 7 & \\
\hline \multicolumn{6}{|c|}{ Within 3 m: } \\
\hline Surfaces & 1 & 94 & 0 & 95 & \multirow[t]{2}{*}{$1 / 101$ (I\%) } \\
\hline Air & 0 & 6 & 0 & 6 & \\
\hline Total & 7 & 317 & 0 & 324 & $7 / 324$ (2.2\% \\
\hline
\end{tabular}

Table 2 Origin of the Environmental Samples with Detected SARS-CoV-2 Viral Genome and Clinical Characteristics of Patients Occupying the Rooms

\begin{tabular}{|c|c|c|c|c|c|c|}
\hline No & $\begin{array}{l}\text { Sample and } \\
\text { Distance }\end{array}$ & $\begin{array}{l}\text { CT } \\
\text { Values }\end{array}$ & Clinical Data of Patient Occupying the Room & $\begin{array}{l}\text { Triage } \\
\text { Score }\end{array}$ & $\begin{array}{l}\text { Clinical } \\
\text { Severity }\end{array}$ & AGP \\
\hline 1 & Table (I m) & 37 & \multirow{4}{*}{$\begin{array}{l}61 \text { years old male, with diabetes mellitus type } 2 \text {, HTN, presented with } \\
\text { fever, cough, sore throat, and dyspnea, admitted to the ICU due to } \\
\text { hypoxic respiratory failure, } \\
\text { CT Value on admission: } 22\end{array}$} & \multirow[t]{4}{*}{15} & \multirow[t]{4}{*}{ Severe } & \multirow[t]{4}{*}{ HFNC } \\
\hline 2 & Phone (I m) & 37 & & & & \\
\hline 3 & $\begin{array}{l}\text { Vital signs machine } \\
(2 \mathrm{~m})\end{array}$ & 39 & & & & \\
\hline 4 & Door knop (3 m) & 41.5 & & & & \\
\hline 5 & Table (I m) & 40 & \multirow{2}{*}{$\begin{array}{l}72 \text { years old male, HTN, post percutaneous coronary intervention, } \\
\text { presented with fever, cough, dyspnea, nausea, myalgia, and diarrhea, } \\
\text { admitted to the ICU (hypoxic respiratory failure), } \\
\text { CT Value on admission: } 40\end{array}$} & \multirow[t]{2}{*}{15} & \multirow[t]{2}{*}{ Severe } & \multirow[t]{2}{*}{ HFNC } \\
\hline 6 & $\begin{array}{l}\text { Vital signs machine } \\
(\mathrm{I} \mathrm{m})\end{array}$ & 40 & & & & \\
\hline 7 & Air $(2 \mathrm{~m})$ & 35.7 & $\begin{array}{l}79 \text { years old male, HTN, presented with productive cough, dyspnea and } \\
\text { fever. } \\
\text { On a fluid resistant surgical face mask type IIR, } \\
\text { CT Value on admission: } 39\end{array}$ & 9 & Mild & None \\
\hline
\end{tabular}

Abbreviations: CT, cycle of threshold; AGP, aerosol generating procedure, HTN, hypertension; HFNC, high flow nasal cannula.

\section{Discussion}

Institutions have implemented various enhanced environmental disinfection procedures for areas with known or suspected COVID-19 cases to prevent secondary transmission. In some facilities, adjunctive disinfection methods are routinely used such as AHP. Although hydrogen peroxide products have been used to reduce airborne transmission of pathogens such as mycobacteria, its broad spectrum and clinical utility for reducing transmission of SARS-CoV-2 is uncertain. In this study, we performed environmental assessment of the effectiveness of AHP decontamination in the COVID-19 facility. Our data generated a before-and-after decontamination map that demonstrated a low initial positivity rate of $2.2 \%$ (Table 1 ). The detection of environmental viral RNA is consistent with previous studies that collected similar samples, although rates of environmental SARS-CoV -2 detection were higher in most published studies (11$56 \%){ }^{2,5,6,19}$ Notably, only one out of a hundred air samples 


\section{Spearman's Correlation}

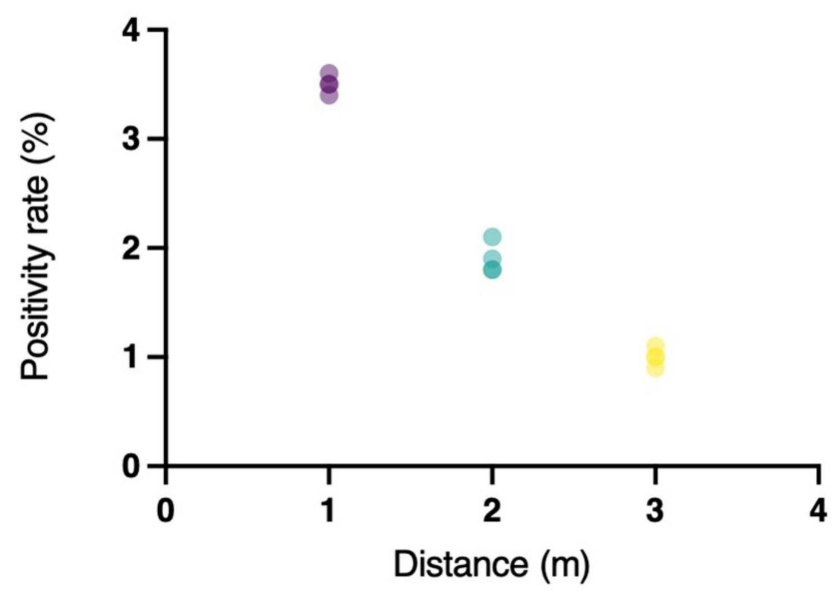

Figure I Spearman correlation study between sampling distance and positivity of SARS- CoV-2 genome detection in 324 environmental hospital samples. Rho= $-0.976(95 \% \mathrm{Cl}=-0.995$ to $-0.939, P$-value $=0.02)$. It illustrates the closer the sites to the patient, the higher the fraction of positive samples amongst tested samples.

taken from occupied rooms by COVID-19 symptomatic cases tested positive, which originated from a maskwearing mild case, with a high CT value suggesting minimal shedding in air (Table 2). While early studies suggested the potential for airborne transmission of the virus, cumulative literature supports its droplet transmission in the absence of aerosol generating procedures, despite the potential for longer distance airborne transmission in poorly ventilated places. ${ }^{20}$ It has been proposed that a continuum of droplet sizes in the exhaled air can play a role in the spread of SARSCoV-2 up to 6-8 meters from an infected source in the absence of adequate airflow, although the clinical relevance of this experimental model in uncertain. ${ }^{21}$ An intensive carebased study has detected the viral genome in air samples at a distance of 4 meters from the infected source. ${ }^{22}$ On the other hand, several studies failed to isolate the virus or its genome through air sampling of patients occupied facilities despite the use of efficient air biosamplers and not only air filter swabbing. 6,23,24 Based on an aerodynamic analysis model in Wuhan hospitals, the SARS-CoV-2 droplets were found to include two size ranges, one in the submicrometer region $(0.25$ and $1.0 \mu \mathrm{m})$ and the other in supermicrometer region $(>2.5 \mu \mathrm{m}){ }^{25}$ Thus, the smaller droplets are likely to be detected at a distance of $\geq 1$ meter. Further studies are needed to explore the frequency of exhaling those smaller droplets in the absence of aerosol generating procedures. Our results do not suggest that severe cases shed more viruses than mild patients in the surrounding environment.
Safe transmission mitigation measures in healthcare facilities depend on multiple factors related to both the infected source, exposed individual, and the environment including distance from the patient, viral load, duration of exposure, performance of aerosol generating procedures, level of room ventilation, use of protective equipment, and the susceptibility status to the virus. The detection of SARS-CoV-2 shedding was directly proportional to physical distance from the patient (Figure 1) as expected, particularly for indoor settings. Nevertheless, the air sample at 2 meters that showed evidence of viral shedding in this study highlights the importance of air hygiene with maximal achievable air change rates per hour. For this purpose, smaller patients' isolation rooms will maximize ventilation. $^{26}$ This, along with routine infection preventive measures, such as effective hand hygiene, HEPA air filters, use of PPE and regular surface decontamination, are likely to eliminate any healthcare acquisition of SARS-CoV-2 from an environmental reservoir. The data also indicates the necessity of thorough terminal cleaning of a COVID-19 patient's room during a pandemic, despite the high turnover, as implicating droplet precautions may not sufficiently mitigate the spread of SARS-CoV-2 if environmental surfaces are not ultimately decontaminated.

The post-decontamination data shown in Table 1 illustrates the efficacy of AHP in removing SARS-CoV-2 viral RNA from surfaces in a hospital environment. This finding supports the hospitals need to at least consider utilizing one aerosolbased, automated strategy in addition to droplet- and contactbased strategies for containment of SARS-CoV-2 particles, especially during an active wave of infection. Alternative tools available for eliminating SARS-CoV-2 from contaminated surfaces include intensified ultraviolet light and ozone gas. ${ }^{27}$ However, data is still emerging with regard to the efficacy of their widespread, standardized application to replace current methods and should be examined for the costeffectiveness. As more waves of viral resurgence are a possibility with the increasing number of notable virus mutants, healthcare facilities need to consider adopting an efficacious system capable of timely eliminating the virus. The fact that the qPCR technique allows SARS-CoV-2 detection at low concentrations can be useful as an indicator of efficacy of environmental and air decontamination. As the automated, non-touch systems, like the dry mist of AHP used in the study, are increasingly being integrated into hospital disinfection policies, ${ }^{28}$ careful evaluation of efficacy needs to be studied. A systematic review performed by Falagas et $\mathrm{al}^{29}$ highlighted the fact of organism-specific efficacy of AHP, mandating ongoing assessment of the technology against 
various pathogens and mutant forms. In addition, certain factors need to be considered when evaluating disinfecting processes which are capable of inactivating SARS-CoV-2 after a short contact time, eg, AHP including temperature, humidity, the size of the initial inoculum, and duration of viral shedding. ${ }^{7}$ An intensive care-based study has found a higher positivity rate was noted following routine decontamination by hydrogen peroxide wipes and ammonium chloride-based solutions, ${ }^{27}$ However, our study was performed in an airborne isolation facility with $\mathrm{ACH}$ of 15 with lesser chance to accumulate viral droplets. This highlights the fundamental role of appropriate building engineering control and infrastructure of healthcare facilities at the design phase in order to promote higher ventilation and enhanced air change rates.

The main limitation of the presented work is the difficulty to conclude viability of the emerging virus through molecular detection of RNA extracted from the collected samples, since viral nucleic acid detection does not necessarily indicate the presence of infectious virus. ${ }^{30}$ Nevertheless, infectious particles are a concern on the environmental surfaces at least immediately after shedding since the SARS-CoV-2 persist for a variable period between $2-18$ hours, while other members of Coronaviridae have shown maintained viability for several days on such surfaces. ${ }^{3,4,7,13}$ Thus, an intermittent environmental sampling approach, both active and passive methods, is worthwhile in order to prevent cross-transmission, since dissemination of SARS-CoV-2 not only can occur through direct contact but also through aerosolized-viral particles over a short distance and touching a viable virion on surfaces. Effective control of the continued spread of SARS-CoV-2 infection needs to consider all these reservoirs of the infection. This will also help in identifying high-risk fomites in individual institutions.

\section{Conclusion}

In summary, we established a method for environmental sampling in COVID-19 isolation wards to objectively assess the decontamination procedures used within institutions to eradicate SARS-CoV-2 from the facility. Although our data demonstrated the presence of RNA of the SARS-CoV-2 in the hospital environment, suggesting a potential reservoir of the infection in cases of epidemics even in the case of a mild disease, this has to be verified in future viability studies. We provided evidence that the automated AHP systems are an effective adjunct to conventional methods of terminal decontamination, and that AHP has the potential to reduce viral transmission in epidemic settings. Further exploration of the optimal, standardized application and cost effectiveness of automated decontamination systems in healthcare settings is required, as such expensive technologies can potentially save resources if systematic evaluation demonstrates consistent efficiency in breaking the chain of nosocomial transmission. In addition, forthcoming studies should also compare the efficacy of various combinations of interventions in mitigating the spread of SARS-CoV-2.

\section{Acknowledgments}

The authors would like to thank the Deanship of Scientific Research at Imam Abdulrahman Bin Faisal University (IAU) for funding this study (Grant no COVID-19-2020008-Med).

\section{Disclosure}

The authors report no conflicts of interest in this study.

\section{References}

1. Stokes EK, Zambrano LD, Anderson KN, et al. Coronavirus disease 2019 case surveillance - United States, January 22-May 30, 2020. MMWR Morb Mortal Wkly Rep. 2020;69:759-765. doi:10.15585/ mmwr.mm6924e2

2. Ong SWX, Tan YK, Chia PY, et al. Air, surface environmental, and personal protective equipment contamination by severe acute respiratory syndrome Coronavirus 2 (SARS-CoV-2) from a symptomatic patient. JAMA. 2020;323:1610-1612. doi:10.1001/jama.2020.3227

3. van Doremalen N, Bushmaker T, Morris DH, et al. Aerosol and surface stability of SARS-CoV-2 as compared with SARS-CoV-1. N Engl J Med. 2020;382:1564-1567. doi:10.1056/NEJMc2004973

4. Rabenau HF, Cinatl J, Morgenstern B, Bauer G, Preiser W, Doerr HW. Stability and inactivation of SARS coronavirus. Med Microbiol Immunol. 2005;194:1-6. doi:10.1007/s00430-004-0219-0

5. Yung CF, Kam KQ, Wong MSY, et al. Environment and personal protective equipment tests for SARS-CoV-2 in the isolation room of an infant with infection. Ann Intern Med. 2020;173:240-242. doi:10.7326/M20-0942

6. Yamagishi T, Ohnishi M, Matsunaga N, et al. Environmental sampling for severe acute respiratory syndrome Coronavirus 2 during a COVID-19 outbreak on the Diamond Princess Cruise Ship. J Infect Dis. 2020;222:1098-1102. doi:10.1093/infdis/jiaa437

7. Kampf G, Todt D, Pfaender S, Steinmann E. Persistence of coronaviruses on inanimate surfaces and their inactivation with biocidal agents. J Hosp Infect. 2020;104:246-251. doi:10.1016/j. jhin.2020.01.022

8. Control, C.f.D. Disinfecting building facility. Available from: https:// www.cdc.gov/coronavirus/2019-ncov/community/disinfectingbuilding-facility.html. Accessed August 5, 2021.

9. Heckert RA, Best M, Jordan LT, Dulac GC, Eddington DL, Sterritt WG. Efficacy of vaporized hydrogen peroxide against exotic animal viruses. Appl Environ Microbiol. 1997;63:3916-3918. doi:10.1128/aem.63.10.3916-3918.1997

10. Orlando P, Cristina ML, Dallera M, Ottria G, Vitale A, Badolati G. Surface disinfection: evaluation of the efficacy of a nebulization system spraying hydrogen peroxide. J Prev Med Hyg. 2008;49:116-119.

11. Shapey S, Machin K, Levi K, Boswell TC. Activity of a dry mist hydrogen peroxide system against environmental Clostridium difficile contamination in elderly care wards. $J$ Hosp Infect. 2008;70:136-141. doi:10.1016/j.jhin.2008.06.008 
12. Otter JA, Yezli S, French GL. The role played by contaminated surfaces in the transmission of nosocomial pathogens. Infect Control Hosp Epidemiol. 2011;32:687-699. doi:10.1086/660363

13. Bedrosian N, Mitchell E, Rohm E, et al. A systematic review of surface contamination, stability, and disinfection data on SARS-CoV2 (Through July 10, 2020). Environ Sci Technol. 2021;55:4162-4173. doi:10.1021/acs.est.0c05651

14. Andersen BM, Rasch M, Hochlin K, Jensen FH, Wismar P, Fredriksen JE. Decontamination of rooms, medical equipment and ambulances using an aerosol of hydrogen peroxide disinfectant. J Hosp Infect. 2006;62:149-155. doi:10.1016/j.jhin.2005.07.020

15. Authority, P.H. COVID -19 Coronavirus National Guidelines. Available from: https:/covid19.cdc.gov.sa/professionals-healthworkers/covid-19-coronavirus-disease-guidelines-en/. Accessed August 5.

16. Miriam K, Lonon I. Bioaerosol Sampling (Indoor Air) Culturable Organisms: Bacteria, Fungi, Thermophilic Actinomycetes. NIOSH Manual of Analytical Methods (NMAM), Fourth Edition; 2003.

17. Zou L, Ruan F, Huang M, et al. SARS-CoV-2 viral load in upper respiratory specimens of infected patients. $N$ Engl J Med. 2020;382:1177-1179. doi:10.1056/NEJMc2001737

18. Mukaka MM. Statistics corner: a guide to appropriate use of correlation coefficient in medical research. Malawi Med J. 2012;24:69-71.

19. Chia PY, Coleman KK, Tan YK, et al. Detection of air and surface contamination by SARS-CoV-2 in hospital rooms of infected patients. Nat Commun. 2020;11:2800. doi:10.1038/s41467-02016670-2

20. Klompas M, Baker MA, Rhee C. Airborne transmission of SARS-CoV-2: theoretical considerations and available evidence. JAMA. 2020;324(5):441. doi:10.1001/jama.2020.12458

21. Stadnytskyi V, Bax CE, Bax A, Anfinrud P. The airborne lifetime of small speech droplets and their potential importance in SARS-CoV-2 transmission. Proc Natl Acad Sci U S A. 2020;117:11875-11877. doi:10.1073/pnas.2006874117
22. Guo ZD, Wang ZY, Zhang SF, et al. Aerosol and surface distribution of severe acute respiratory syndrome Coronavirus 2 in Hospital Wards, Wuhan, China, 2020. Emerg Infect Dis. 2020;26:1583-1591. doi:10.3201/eid2607.200885

23. Lane MA, Brownsword EA, Morgan JS, et al. Bioaerosol sampling of a ventilated patient with COVID-19. Am J Infect Control. 2020;48:1540-1542. doi:10.1016/j.ajic.2020.07.033

24. Ahn JY, An S, Sohn Y, et al. Environmental contamination in the isolation rooms of COVID-19 patients with severe pneumonia requiring mechanical ventilation or high-flow oxygen therapy. $J$ Hosp Infect. 2020;106:570-576. doi:10.1016/j.jhin.2020.08.014

25. Liu Y, Ning Z, Chen Y, et al. Aerodynamic analysis of SARS-CoV-2 in two Wuhan hospitals. Nature. 2020;582:557-560. doi:10.1038/ s41586-020-2271-3

26. Chartier Y, Pessoa-Silva CL. Natural Ventilation for Infection Control in Health-Care Settings; 2009. ISBN-13: 978-92-4-154785-7

27. Brune Z, Kuschner CE, Mootz J, et al. Effectiveness of SARS-CoV-2 decontamination and containment in a COVID-19 ICU. Int J Environ Res Public Health. 2021;18:2479. doi:10.3390/ijerph18052479

28. Passaretti CL, Otter JA, Reich NG, et al. An evaluation of environmental decontamination with hydrogen peroxide vapor for reducing the risk of patient acquisition of multidrug-resistant organisms. Clin Infect Dis. 2013;56:27-35. doi:10.1093/cid/cis839

29. Falagas ME, Thomaidis PC, Kotsantis IK, Sgouros K, Samonis G, Karageorgopoulos DE. Airborne hydrogen peroxide for disinfection of the hospital environment and infection control: a systematic review. $J$ Hosp Infect. 2011;78:171-177. doi:10.1016/j. jhin.2010.12.006

30. Wölfel R, Corman VM, Guggemos W, et al. Virological assessment of hospitalized patients with COVID-2019. Nature. 2020;581:465-469. doi:10.1038/s41586-020-2196-x
Risk Management and Healthcare Policy

\section{Publish your work in this journal}

Risk Management and Healthcare Policy is an international, peerreviewed, open access journal focusing on all aspects of public health, policy, and preventative measures to promote good health and improve morbidity and mortality in the population. The journal welcomes submitted papers covering original research, basic science, clinical \& epidemiological studies, reviews and evaluations, guidelines, expert opinion and commentary, case reports and extended reports. The manuscript management system is completely online and includes a very quick and fair peer-review system, which is all easy to use. Visit http://www.dovepress.com/testimonials.php to read real quotes from published authors. 